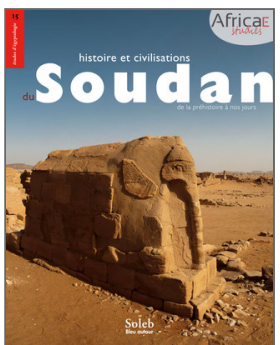

Olivier Cabon (dir.)

Histoire et civilisation du Soudan

De la préhistoire à nos jours

\title{
10. Des « rois grecs » à la peau sombre
}

Les royaumes chrétiens du Soudan médiéval. 543-1500 apr. J.-C.

\section{Claude Rilly}

DOI : $10.4000 /$ books.africae. 2832

Éditeur: Africae, Soleb, Bleu autour

Lieu d'édition : Paris, Khartoum

Année d'édition : 2017

Date de mise en ligne : 17 janvier 2022

Collection : Africae Studies

EAN électronique : 9782493207074

\section{OpenEdition}

\section{Books}

http://books.openedition.org

\section{Référence électronique}

RILLY, Claude. 10. Des « rois grecs » à la peau sombre : Les royaumes chrétiens du Soudan médiéval. 543-1500 apr. J.-C In : Histoire et civilisation du Soudan : De la préhistoire à nos jours [en ligne]. Paris, Khartoum : Africae, 2017 (généré le 28 janvier 2022). Disponible sur Internet : <http:// books.openedition.org/africae/2832>. ISBN : 9782493207074. DOI : https://doi.org/10.4000/ books.africae.2832. 
des "rois grecs"

à la peau sombre

les royaumes chrétiens

du Soudan médiéval

543-1500 apr. J.-C. 
L'une des constantes des États qui se sont succédé sur le territoire du Soudan depuis la chute de Kerma est d'avoir toujours voulu se conformer à des modèles culturels étrangers: l'Égypte pharaonique pour les royaumes koushites, l'Empire byzantin pour les royaumes chrétiens médiévaux, les monarchies du Golfe aujourd'hui. L'influence byzantine sur le Soudan du Moyen Âge est particulièrement visible dans l'épigraphie: les pierres tombales des autorités ecclésiastiques et politiques sont ainsi le plus souvent rédigées en grec (plus rarement en copte). Mais elle est aussi confirmée par les récits des chroniqueurs chrétiens orientaux et arabes, qui sont nos sources principales sur l'histoire de cette période. Ainsi, Jean Diacre l'Égyptien nous apprend que le roi de Makouria Merkourios était surnommé le "Nouveau Constantin». Un auteur arabe appelle le monarque nubien «le roi grec» (al-malik al-yunani).

Toutefois, pas plus que le modèle égyptien ne remettait en cause les coutumes particulières des Koushites, l'influence grecque n'effaçait les spécificités locales. Assez vite, les langues nubiennes furent écrites à l'aide d'un alphabet inspiré du copte et les Saintes Écritures traduites au moins en partie en vieux-nubien, la langue du nord. Sur les peintures murales des églises, face aux personnages de l'Ancien et du Nouveau Testament représentés avec la peau claire, les rois, les princes et les évêques de Nubie tranchent par leur carnation sombre. La Nubie et l'Éthiopie (l'ex-Abyssinie) représentent en effet les deux grands ensembles chrétiens de l'Afrique noire médiévale, même si en Occident on oublie souvent que le Soudan, avant de céder face à l'islam, a connu un millénaire de chrétienté.

des origines

à la chute

du sultanat

\section{La conversion des royaumes nubiens au christianisme}

Fung

$\mathrm{Au}$ milieu du $\mathrm{VI}^{\mathrm{e}}$ siècle, trois royaumes nubiens se partagent la Vallée du Nil moyen, après avoir absorbé ou fédéré les principautés noubas bien plus nombreuses de l'époque postméroïtique. Au nord, en amont de la première cataracte, limitrophe de l'Égypte, se trouve le royaume de Nobadia (ou Nobatia), avec sa capitale à Qasr Ibrim et plus tard à Faras. Au centre, entre la troisième cataracte et la cinquième, s'étend le royaume de Makouria, dont la capitale est Old Dongola. Enfin, au sud de la cinquième cataracte et jusqu'au-delà de l'actuel Khartoum, se trouve le royaume d'Alodia (ou Alwa), avec sa capitale à Soba sur le Nil Bleu, non loin de la confluence avec le Nil Blanc. Enfin, le désert Arabique jusqu’à la mer Rouge est toujours tenu par les Blemmyes et les Bedjas, entre lesquels les sources écrites ne font plus de différence. C'est cette situation politique complexe que trouvent les premiers missionnaires envoyés par Constantinople. 
$\mathrm{Si}$, comme nous l'avons vu dans le chapitre précédent, le christianisme n'était pas inconnu dans le royaume des Noubades, le Soudan n'était pas non plus étranger aux textes fondamentaux de la nouvelle foi. Dans l'Ancien Testament, le pays de Koush était à maintes reprises cité sous son nom classique d'Aithiopia dans la version grecque des Septante, notamment dans le Livre d'Ésaïe et dans le Psaume 68 (Septante: 67), où il est dit que «l'Éthiopie tendra sa main vers Dieu». Il ne s’agit évidemment jamais de l'Éthiopie actuelle, malgré les tentatives éhontées de récupération des Abyssins qui allèrent jusqu'à revendiquer Taharqo comme un de leurs anciens rois. Dans le Nouveau Testament, les Actes des Apôtres (8/27-39) racontent une bien curieuse histoire. Vers 37 de notre ère, le diacre Philippe rencontre un «Éthiopien, un eunuque, haut fonctionnaire de Candace, reine d'Éthiopie, en charge de tous ses trésors", qui s'en revient d'un pèlerinage à Jérusalem par la route de Gaza, tout en lisant dans son char le livre d'Ésaïe. Philippe le convertit et le baptise à sa demande. Il est peu probable que cette anecdote soit authentique, sauf à croire que la reine Nawidémak ait employé comme trésorier un eunuque probablement d'origine étrangère (la castration n'est pas attestée au Soudan ancien) et converti une première fois au judaïsme, ce qui suppose une conjonction de situations toutes extraordinaires.

Aux $\mathrm{V}^{\mathrm{e}}$ et $\mathrm{VI}^{\mathrm{e}}$ siècles, l'un des schismes les plus durables de la chrétienté se produisit. La question était de savoir si le Christ possèdait une nature unique hybride, à la fois divine et humaine, ou deux natures séparées, l'une divine et l'autre humaine. Les tenants de la première thèse sont dits "monophysites», ceux qui soutiennent la seconde, «dyophysites» ou "melkites», car cette position était celle de l'empereur de Constantinople, en syriaque malka, «le roi». En 451, l'empereur Marcien fit condamner lors du concile de Chalcédoine les monophysites comme hérétiques, causant la scission de l'Église égyptienne (dite copte) et éthiopienne du christianisme officiel. Près d'un siècle plus tard, les deux dogmes coexistaient encore au cour même de Constantinople et au plus haut lieu, le couple impérial. L’empereur Justinien, évidemment de confession melkite, avait épousé en effet une femme au destin extraordinaire, Théodora. Ancienne dompteuse de cirque, puis courtisane renommée, elle était issue d'une famille monophysite et resta fidèle à ses convictions, même après l'accession au trône de son époux en 527. Elle protégea notamment Théodose, le patriarche d'Alexandrie, monophysite, qui avait été démis et exilé par Justinien. Cette fidélité à sa foi va jouer un rôle capital dans l'histoire du Soudan médiéval. Comme nous l'avons vu au chapitre précédent, Justinien avait ordonné vers 535-537 la fermeture définitive des temples de Philae en Basse-Nubie, qui furent transformés en église. C'est peut-être là que mûrit l'idée d'une conversion officielle des Nubiens au christianisme, 
le Soudan

\section{6}

des origines

à la chute

du sultanat

Fung à commencer par le royaume limitrophe de Nobadia. À Constantinople, un prêtre monophysite nommé Julien s'en ouvrit à Théodora. La suite (voir ci-contre) nous est contée par Jean d'Éphèse, évêque monophysite de cette ville, qui rédigea en syriaque une Histoire ecclésiastique, l'une de nos sources principales sur le règne de Justinien.

Les faits rapportés par Jean d'Éphèse sont clairs et abondamment documentés (nous n'en avons ci-contre traduit qu'une partie), si bien que son récit a passé depuis longtemps comme une source historique suffisante pour attester la conversion de la Nubie: en 543, le royaume de Nobadia aurait été converti par Julien, passant ainsi directement du paganisme au christianisme, et, en 580, le royaume d'Alodia l'aurait été par Longin, nouvel évêque de Nobadia. Une inscription commémorant la conversion en église du temple de Dendur confirme de plus cette version des faits. Elle cite en effet l'évêque de Philae Théodore, à qui, vers 546, Julien avait confié ses nouvelles ouailles. Elle est inscrite en copte, langue de l'Église monophysite d'Égypte. Qui plus est, elle est rédigée au nom d'un roi nommé Eirpanomé, qui est sans doute celui que le texte syriaque (non vocalisé) de Jean d'Éphèse appelle Wrpywl.

Toutefois, le but de l'auteur de l'Histoire ecclésiastique est avant tout de produire une défense et illustration de la foi monophysite en racontant ses épreuves et en exaltant ses victoires. Même si l'aspect officiel de la conversion de Nobadia en 543 est difficilement réfutable, il est possible qu'une pénétration massive de la foi chrétienne dans le royaume se soit produite dès le début $\mathrm{du} \mathrm{VI}^{\mathrm{e}}$ siècle, ainsi que semblent en témoigner plusieurs indices archéologiques comme l'apparition de tombes chrétiennes et l'incision de croix sur les céramiques. L'initiative de Julien à Constantinople et surtout la décision de Théodora s'expliqueraient alors par une course de vitesse pour éviter qu'un État melkite de Nubie ne flanque au sud ce bastion du monophysisme qu'était alors l'Égypte.

Mais, surtout, Jean d'Éphèse ne souffle mot de la conversion du royaume de Makouria. Son témoignage montre clairement que, si les monarques de Nobadia et Alodia étaient alliés, le royaume situé entre eux, Makouria, était leur ennemi commun. La réaction des Makourites face à l'expédition de Longin vers Alodia, qu'ils cherchent à empêcher par tous les moyens, se comprend mieux si l'on suppose que, dans l'espace de temps situé entre 543 et 580, ce pays avait été converti à la foi melkite. Cette conversion pourrait avoir été le fait de la première mission envoyée par Justinien, qui était arrivée trop tard en Nobadia mais avait peut-être poursuivi sa route vers Old Dongola, ou plus vraisemblablement d'une seconde misssion expédiée un peu plus tard. Bien évidemment, ce succès des missionnaires melkites aurait été omis à dessein par Jean d'Éphèse. Semblablement, 


\section{La conversion des royaumes nubiens}

Jean d'Éphèse, Histoire ecclésiastique III, extraits.

D'après les traductions anglaises de G. Vantini, Oriental Sources

concerning Nubia, Heidelberg-Varsovie, 1975, et de R. Payne Smith, The Third Part of the Ecclesiastical History, Oxford, 1860

L'empereur, ayant appris qu'elle (Théodora) s'apprêtait à dépêcher quelqu'un de cette Église opposée à lui (monophysite), en fut contrarié. Il fit rédiger une lettre destinée à ses évêques dans la région de la Thébaïde, leur enjoignant d'entrer sur ce territoire et d'instruire les gens tout en évitant de mentionner cette Église. Empli lui-même de zèle, il envoya immédiatement des ambassadeurs chargés d'or, de vêtements baptismaux et de présents destinés au roi de ce peuple, et des lettres au gouverneur de la Thébaïde pour qu'il prenne soin des ambassadeurs et les fassent guider vers ce peuple. Aussi, dès qu'elle eut connaissance de cela, elle (Théodora) écrivit une lettre astucieusement rédigée au gouverneur de la Thébaïde, qui lui fut remise par un officiel. La teneur de cette missive était telle: «Attendu que Sa Majesté et moi-même avons décidé d'envoyer une ambassade au peuple des Noubades, je dépêche à cet effet un saint homme nommé Julien. De plus, je veux que mon ambassadeur arrive auprès dudit peuple avant celui de Sa Majesté. Sache que, si tu permets que son ambassadeur arrive avant le mien et que tu ne l'en empêches pas en usant de prétextes variés jusqu'à ce que le mien soit parvenu jusqu'à toi, ait traversé ta province et soit arrivé à destination, tu m'en répondras sur ta vie, car j'enverrai immédiatement quelqu'un te couper la tête.»

Lorsque le gouverneur de la Thébaïde lut cela et que l'ambassadeur de l'empereur fut parvenu auprès de lui, il l'abusa en disant: «Attendez patiemment que nous nous procurions les chameaux, que nous les équipions et trouvions des hommes qui connaissent la piste du désert. Vous les aurez ensuite à disposition et entrerez dans ce pays. » Il le congédia donc et attendit l'arrivée des envoyés de la noble impératrice. Ces derniers trouvèrent les chameaux prêts et les guides et, le jour même, sans attendre, ils feignirent de s'emparer par la force des chameaux et partirent les premiers. Le gouverneur fit porter alors un message à l'ambassadeur de l'empereur: «Alors que j'avais terminé les préparatifs et voulais vous faire partir, voilà que des envoyés de l'impératrice sont arrivés, m’ont assailli, se sont emparés des bêtes de somme que j'avais préparées et ont continué leur chemin. Je ne connais que trop la crainte qu'inspire l'impératrice pour risquer de m'opposer à eux. Restez toutefois avec moi, le temps que je puisse recommencer les préparatifs pour vous, et vous pourrez vous aussi prendre la route en paix.» L'ambassadeur 
de l'empereur, à ces mots, déchira ses vêtements et se répandit en menaces et en insultes. Quelques jours après, il put se mettre en route à son tour et partit enfin sans s'être aperçu du tour qu'on lui avait joué.

Quand Julien et les envoyés qui l'accompagnaient eurent atteint le pays et eurent fait prévenir de leur arrivée le roi et ses princes, une armée entière fut dépêchée à leur rencontre. Ils reçurent l'expédition de Julien avec joie et les amenèrent devant le roi, qui les accueillit tout aussi cordialement. Alors Julien présenta les lettres de l'Impératrice, qui furent lues et dont le contenu fut expliqué. Ils acceptèrent aussi les cadeaux et les vêtements baptismaux, tout étant en abondance. Ils s'offrirent aussitôt volontiers à l'instruction, renonçant aux errements de leurs pères et confessant le dieu des chrétiens en disant: "C'est lui le vrai Dieu unique et il n'y en a pas d'autre à part lui.» Après leur avoir donné une instruction et une formation complètes, le groupe de Julien les informa aussi que certaines disputes s'étaient soulevées entre chrétiens à propos d'un point de dogme particulier, que, pour cette raison, même le bienheureux Théodose [d'Alexandrie] s'était vu enlever son diocèse par l'empereur pour avoir refusé d'obtempérer mais que la reine l'avait soutenu vaillamment. Ils ajoutèrent: «Elle nous a envoyés vers vous avec cette foi pour que vous suiviez le patriarche Théodose, receviez le baptême conformément à sa foi et en préserviez la vérité. Mais l'empereur a aussi dépêché une ambassade qui va arriver après nous.» Alors ils enseignèrent aux Noubades comment les recevoir et que leur répondre.

Tandis qu'ils venaient juste de les instruire de tous ces détails,

des origines

à la chute

du sultanat

Fung l'ambassadeur de l'empereur arriva. Il présenta semblablement au roi les lettres et les cadeaux et commença à l'informer en lui disant, selon les instructions qu'il avait reçues: «L'empereur des Romains nous a envoyés vers vous afin que, si vous deveniez chrétiens, vous soyez fidèles à son Église et ne vous laissiez pas détourner par ceux qu'il en a expulsés.» Quand le roi des Noubades et ses princes entendirent ces paroles, ils répondirent: «Ce présent honorable que nous a envoyé l'empereur des Romains, nous l'acceptons et nous lui enverrons nous-mêmes un présent. Mais quant à sa foi, nous ne pouvons l'accepter. Car si nous consentons à devenir chrétiens, nous suivrons la trace du patriarche Théodose qui, parce qu'il ne voulut accepter la foi mauvaise de l'empereur, fut par lui exilé et expulsé de son Église. Aussi, si nous renonçons à notre paganisme et nos errements, nous ne pouvons consentir à tomber dans la foi mauvaise professée par l'empereur.» Alors ils renvoyèrent l'ambassade et firent mettre tout cela par écrit.

Le bienheureux Julien resta deux ans parmi eux, supportant des chaleurs torrides. Il déclara plus tard qu'il avait l'habitude de demeurer de la troisième à la dixième heure [ 9 heures à 16 heures] dans des cavernes 
pleines d'eau avec tout le peuple de la région, nu ou plutôt seulement vêtu d'un drap, tant qu'il ne pouvait transpirer qu'avec l'aide de l'eau. Malgré cela, il persévéra, instruisit et baptisa le roi et ses nobles et beaucoup de gens avec eux. Il réussit aussi à faire venir à ses côtés un certain évêque de la Thébaïde, un vieil homme nommé Théodore.

Ayant instruit et organisé la communauté, il la confia à cet évêque, prit congé et revint à Constantinople. J'étais moi-même présent quand l'impératrice le reçut avec les plus grands honneurs. Il racontait sur ce grand peuple des choses merveilleuses, que je ne mentionne pas parce qu'elles sont trop nombreuses, me contentant des quelques éléments que je rapporte ici.

[...] Le patriarche Théodose, le jour de sa mort, se souvint de ce peuple, et ce d'autant plus que le pieux Julien qui les avait évangélisés était décédé et que sa perte était durement ressentie. L’impératrice Théodora également était morte. Aussi, Théodose donna des ordres pour que le pieux Longin prît la place de Julien car Longin était un homme plein de zèle, capable de parachever la conversion des Noubades et de les conforter dans la religion chrétienne. Tout de suite après la mort du patriarche, Longin fut ordonné évêque de ces contrées et se prépara pour le voyage. [...] Lorsqu'il arriva dans ce pays, il fut reçu avec grande joie. Il instruisit à nouveau tout le peuple dans la religion chrétienne, prêchant et éclairant leur esprit. Il fit aussi bâtir une église et installa un clergé, organisa la liturgie et mit en place toutes les institutions ecclésiastiques. [...]

Quand le peuple des Alodiens apprit que les Noubades avaient été convertis, leur roi adressa une lettre au roi des Noubades, lui demandant d'envoyer celui qui avait instruit et baptisé les Noubades, pour qu'il pût évangéliser et baptiser aussi les Alodiens. [...] Lorsque les Alexandrins [les autorités melkites d'Égypte] surent que le roi des Alodiens avait missionné une seconde ambassade auprès du roi des Noubades pour qu'il lui dépêchât Longin, qui avait instruit ses sujets dans la foi, alors, animés d'une jalousie ardente, ils envoyèrent une délégation à ce peuple [les Alodiens] pour les monter contre Longin, introduire chez eux cette ruine et cette transgression de la doctrine ecclésiastique qu'ils avaient initiées et en laquelle ils voulaient les instruire. Ils rédigèrent alors avec soin une lettre fallacieuse pour eux concernant Longin. [...] Ils écrivirent: "Comme nous avons appris que vous avez mandé Longin, actuellement résidant chez les Noubades, pour qu'il vous baptise, nous vous envoyons ces évêques avec d'autres personnes pour vous informer que vous ne devez pas être baptisés par cet homme, qui est un hérétique et a été démis de ses fonctions. Il ne peut donc plus légalement exercer son sacerdoce ni baptiser personne.» Ils ajoutèrent divers propos de la même farine 
le Soudan

\section{0}

des origines

à la chute

du sultanat

Fung pour leur enseigner leurs dangereuses convictions. [...] Les Alodiens dirent aux envoyés: «Nous ne savons pas qui vous êtes, nous ne pouvons vous recevoir et être baptisés par vous; mais nous recevrons celui qui a baptisé les Noubades et c'est lui qui nous baptisera. Quant à ce que vous dites de lui, nous ne l'écoutons pas parce que nous voyons que vous êtes ses ennemis et parlez de lui ainsi par jalousie. Quittez donc notre pays et vous éviterez une mort ignominieuse.

[Extrait de la lettre du roi des Noubades Wrpywl à Théodore, patriarche monophysite d'Alexandrie:]

En raison des desseins pernicieux de celui qui réside entre nous [les Noubades et Alodia], j'entends le roi des Makourites, j'ai envoyé mon saint père [Longin] auprès du roi des Blemmyes pour qu'il le fasse guider jusqu'à destination par les pistes de l'intérieur des terres. Mais les Makourites ont eu vent de cela aussi et ont posté des gens pour surveiller toutes les passes de leur royaume, aussi bien en plaine qu'en montagne et jusqu'à la mer des Roseaux [la mer Rouge], désirant mettre la main sur mon père [Longin] et arrêter l'œuvre bienfaisante de Dieu, comme me l'a écrit mon père. Il a dû endurer des tourments et de dures épreuves physiques et morales dans le pays des Blemmyes, sans compter les souffrances dues aux privations. Malgré tout cela, la navrante malice de l'ennemi ne put détourner des œuvres de Dieu le zèle de mon père. Le Seigneur Dieu lui-même guida sur les chemins et les pistes mon saint père afin qu'il puisse franchir les longues pistes et échapper aux fortes garnisons, même lorsque ses chameaux de bâts et autres bêtes périrent. Avec l'aide de Dieu, il réussit à atteindre le pays et fut reçu par le roi et tout le peuple avec allégresse. Il instruisit le roi et le baptisa, ainsi que tous ceux qui l'accompagnaient, comme il est écrit dans la lettre qu'il m’a envoyée. [...]

Ces faits se produisirent avec l'aide de Dieu en l'année 891 [ère séleucide $=580 \mathrm{apr}$. J.-C.] et furent consignés par nous. 
la réaction violente des Alodiens face aux envoyés d'Alexandrie les prévenant contre Longin s'explique plus facilement si l'on suppose que les Makourites avaient adopté le dogme melkite.

On sait par l'archéologie, d'autre part, que les premières églises d'Old Dongola datent de la seconde moitié du vi siècle, ce qui confirme la christianisation de l'élite makourite peu après 543. De plus, contrairement aux édifices chrétiens les plus anciens de Nobadia, où se ressent l'influence copte égyptienne, ceux de Makouria semblent inspirés de l'architecture byzantine, corroborant l'hypothèse de l'introduction du dogme melkite. Enfin, la chronique en latin de Jean de Biclar, un clerc wisigoth qui avait séjourné à Constantinople, mentionne en l'an 3 de Justin II, successeur de Justinien, soit en 568, que «les Makourites ont reçu la foi du Christ» et qu'en l'an 7 (en 573) une délégation de Makourites, amenant comme cadeaux diplomatiques des défenses d'éléphant et une girafe, fut reçue à Constantinople pour établir un traité d'amitié avec l'Empire byzantin. On pense généralement que cette ambassade avait pour but d'obtenir la création d'un siège épiscopal métropolitain à Old Dongola, mais dans tous les cas elle atteste clairement une conversion toute récente à la doctrine de l'empereur.

\section{De la christianisation à l'annexion de la Nobadia}

Entre la conversion des royaumes chrétiens $(543-580)$ et la première tentative de conquête musulmane en 651-652, nos sources sont extrêmement réduites. Une inscription grecque commémorant la fondation d'une église dans la forteresse d'Ikhmindi, au nord de Qasr Ibrim, cite en 577 un roi des Noubades nommé Tokiltoéton, qui pourrait être le successeur d'Eirpanomé. Mais pour le reste, il faut se tourner vers les témoignages archéologiques. L'adoption officielle du christianisme par les élites nubiennes s'est concrétisée sur le terrain par la construction d'églises et de monastères. En Nobadia, certains de ces bâtiments chrétiens ne sont qu'une récupération et un aménagement de temples païens, comme à Philae, Qasr Ibrim et Dendour. D'autres semblent constituer des édifices nouveaux, comme à Faras, sans doute déjà capitale du royaume noubade. Mais ils réutilisent volontiers des matériaux issus des sanctuaires antiques: ainsi, à Nilwa, une église est bâtie entre les $\mathrm{VI}^{\mathrm{e}}$ et $\mathrm{VII}^{\mathrm{e}}$ siècles à l'aide des blocs et des colonnes du temple de Sedeinga tout proche.

Contrairement à la Nobadia où les centres urbains principaux sont situés sur les anciennes cités koushites, dans les royaumes de Makouria et d'Alodia les lieux où s'installe l'élite nubienne sont le plus souvent des fondations nouvelles, ce qui oblige à construire des édifices religieux 
également nouveaux. Ainsi, à Old Dongola, une première cathédrale est bâtie avant la fin du vi e siècle, suivant un plan basilical qui rappelle certaines églises byzantines de Syrie et de Palestine. Le plafond de bois était supporté par des colonnes de granit extrait des carrières de la troisième cataracte. À plus d'un kilomètre de la cité fut entreprise à la même époque la construction d'un monastère dédié à saint Antoine, le fondateur égyptien du monachisme. Dans le royaume d'Alodia, converti plus tard, il faut attendre le milieu du viI ${ }^{e}$ siècle pour voir surgir de terre à Soba les premiers édifices chrétiens connus. Mais la fouille de l'immense site de la capitale ayant été jusqu'à présent très partielle, on ne peut exclure que des églises aient existé plus tôt.

Dans le domaine funéraire, la mutation qu'amène le christianisme, avec sa conception épurée de la vie dans l'Au-delà, est radicale. Les vastes superstructures laissent place à des fosses étroites orientées ouest-est, parfois munies d'une couverture de briques en forme de banc. Les sacrifices d'animaux et d'humains disparaissent. Les riches trousseaux auparavant inhumés avec le défunt se réduisent dans le meilleur des cas à ses vêtements et ses bijoux. L'usage de cercueils en bois se fait rare, le corps étant le plus souvent enveloppé d'un suaire fréquemment ceinturé de cordes. Il est désormais placé en position allongée, la tête face à l'est. Pour les personnages les plus importants, rois, gouverneurs, évêques, une stèle gravée en grec est érigée sur le tombeau, comportant des passages des Écritures et quelques éléments biographiques. Certains exemplaires en copte appartiennent à des moines, que l'on peut supposer d'origine égyptienne.

En 613, au moment même où, dans la lointaine Arabie, un proà la chute du sultanat Fung phète du nom de Mahomet commençait sa prédication, l'Empire byzantin vacille: ses armées sont battues à Antioche par les troupes du roi perse sassanide Chosroès II, qui occupe ensuite la Syrie. L'année suivante, il s'empare de Jérusalem. En 617-619, l'Égypte à son tour est conquise. Les Sassanides sont alors aux portes de la Nobadia. De 622 à 628, l'empereur Héraclius mène une contre-attaque patiente et efficace, qui s'achève par la défaite et la mort de Chosroès II. L'Égypte est restituée à Constantinople en 629, après une année de négociation avec le général perse qui l’occupait.

Plusieurs spécialistes ont proposé de situer durant cette période d'administration sassanide l'annexion par Dongola de la Nobadia. On sait en effet que les deux royaumes nubiens sont encore distincts et ennemis vers 580 (voir section précédente) mais que les Arabes, lors de leur assaut sur la Nubie en 651, s'attaquent à un royaume unifié. On ignore en revanche les modalités de la conquête de la Nobadia par son voisin du sud. On a prétendu que l'Église copte n'était pas en mesure, durant l'occupation perse, 
ax: $x$

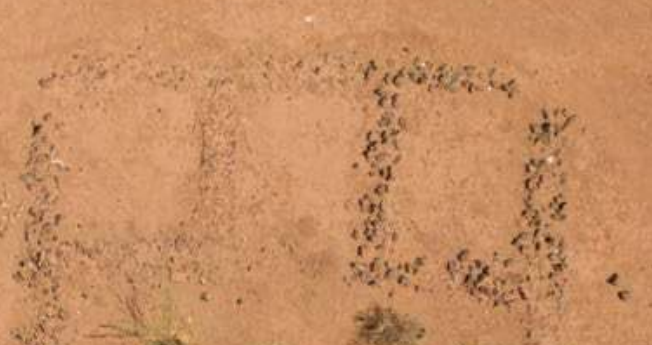

insto

of $x+x$

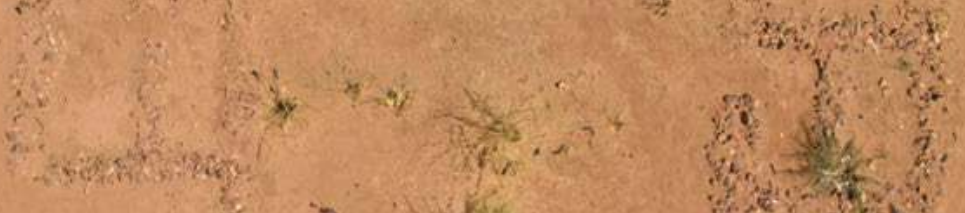

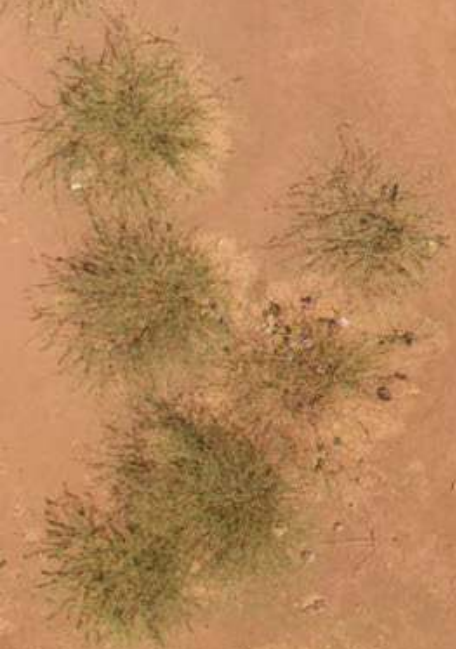

स*

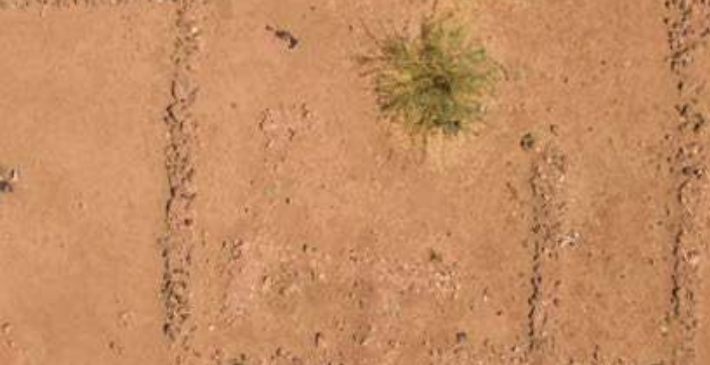

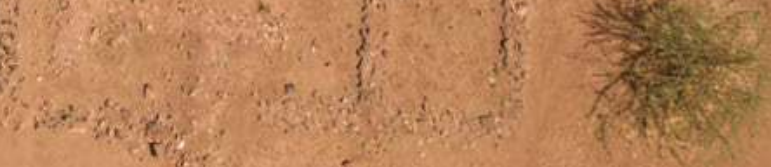

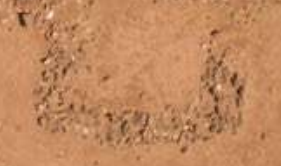

it.
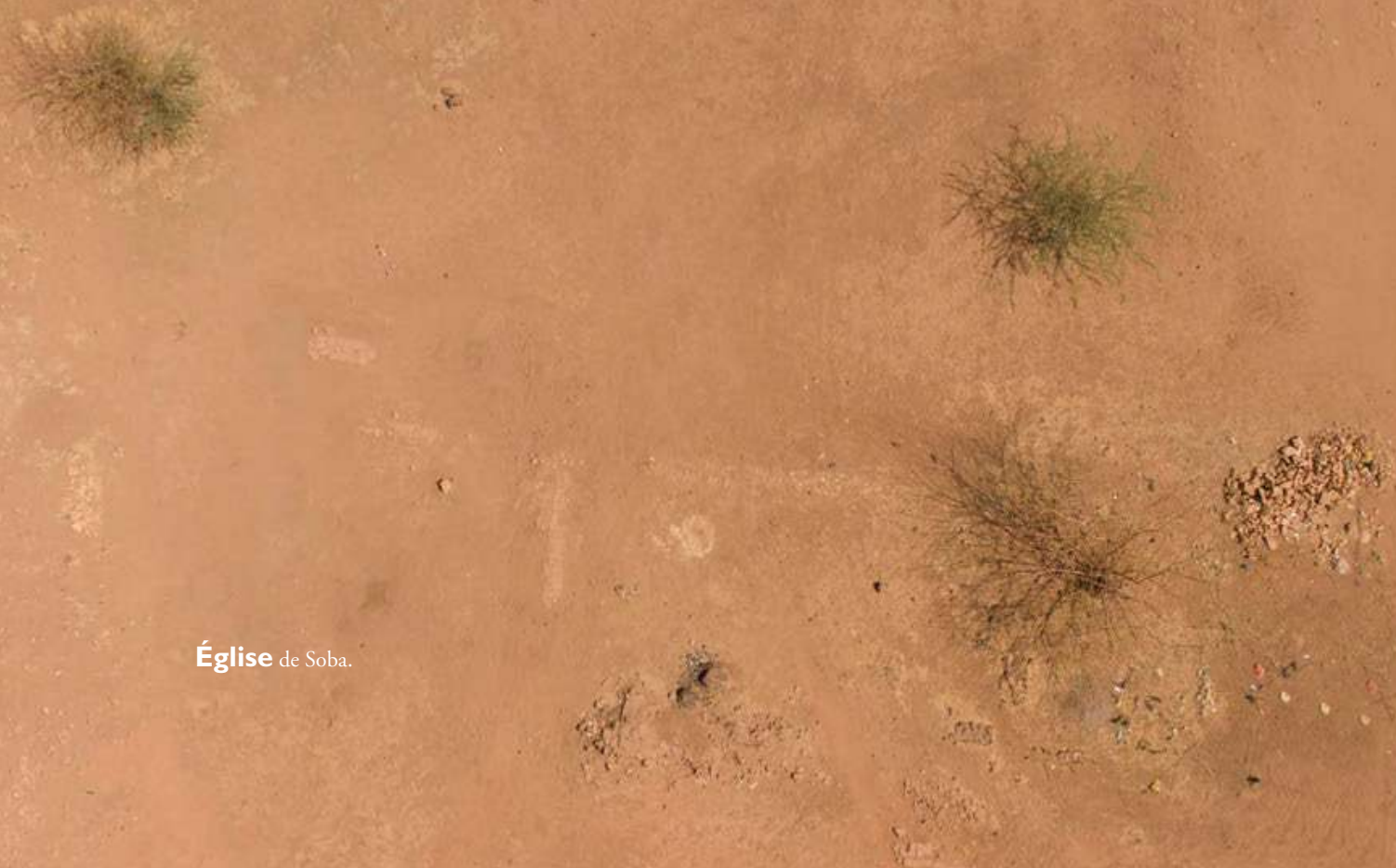

Église de Soba.

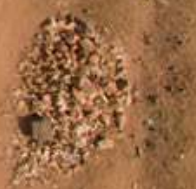

$\therefore$
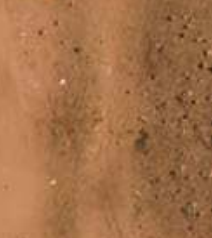
de venir en aide à son alliée la Nobadia. Mais on sait que les occupants sassanides étaient plutôt favorables aux monophysites, habituellement en butte aux persécutions des officiels byzantins, et il faut donc chercher une autre piste.

L'historien persan al-Tabari (839-923) et le polygraphe syrien Bar Hebraeus (1226-1286) rapportent que les Sassanides s'emparèrent d'Alexandrie et de l'Égypte jusqu'à la frontière avec la Nubie, c'est-à-dire le royaume de Nobadia. Après une période initiale de pillages, ils instaurèrent en Égypte une politique plutôt pacifique et renversèrent la balance entre melkites et monophysites au profit de ces derniers. Bien qu'aucune trace écrite n'en ait subsisté, on peut penser que les Noubades trouvèrent en eux un allié, dans leur commune opposition aux Byzantins. Si tel est le cas, c'est plutôt lors du retrait d'Égypte des Sassanides en 629 que Makouria annexa le territoire noubade, profitant d'un vide politique momentané et peut-être de l'assentiment de Constantinople.

Le royaume annexé devint la province de Nobadia. Comme à l'époque de Méroé, le roi de Dongola se fit représenter, sans doute un peu plus tard, dans ce nouveau territoire par un vice-roi. Il était appelé «éparque» de Nobadia, en grec eparkhos, "gouverneur», en vieux nubien songoj. Les Arabes le nommeront "le Seigneur de la Montagne» (sahib al-jabal), qui est peutêtre un calque de son titre nubien songoj, dont l'étymologie est incertaine. Les éparques résidèrent d'abord à Faras, puis à Qasr Ibrim où les fouilles britanniques ont mis au jour une importante correspondance en vieux-nubien issue de leurs archives. Le rôle de l'éparque était double: il administrait la province de Nobadia et constituait le principal relais diplomatique de Makouria avec

des origines

à la chute

du sultanat

Fung l'Égypte, réglant les différends qui pouvaient se produire entre les deux États. Les éparques étaient sans doute choisis par le souverain de Dongola parmi les hauts fonctionnaires du royaume plutôt qu'au sein de la famille royale. Ils étaient cependant entourés d'une cour, à l'instar d'un véritable monarque. Les fresques des cathédrales de Faras et Dongola nous ont conservé plusieurs portraits, que l'on considère traditionnellement comme ceux des éparques de Nobadia, accompagnés du Christ ou de la Vierge. Ils arboraient un costume somptueux et étaient coiffés d'une couronne singulière, flanquée d'une ou deux rangées de cornes et constituée d'une calotte au centre de la laquelle se dressait une tige surmontée d'un croissant de lune.

\section{L'échec de l'invasion arabe de Dongola et le Baqt}

La longue guerre entre Byzantins et Sassanides laissa les deux Empires exsangues. Cette faiblesse explique, plus encore que l'ardeur que leur donnait leur nouvelle foi, les succès rapides des armées de l'Islam en Asie et en Afrique. En 636, quatre ans après la mort de Mahomet, l'Empire sassanide est vaincu. En 638, Jérusalem 
est enlevée à l'Empire byzantin. En 639, avec moins de 20000 hommes, le général arabe Amr Ibn al-'As s'empare de l'Égypte, qui change ainsi de maître pour la troisième fois en à peine plus d'une décennie. Vers 642, une armée musulmane menée par Abdallah Abou Sarh, futur gouverneur de l'Égypte, est à la frontière de Makouria et attaque le pays. Mais la contre-offensive des Nubiens désoriente les Arabes, qui subissent de lourdes pertes. Sur la suite des événements, notre principale source est l'historien égyptien al-Maqrizi (1364-1442), qui écrit huit siècles après les faits, cite probablement l'opuscule (perdu) d'Ibn Sulaym al-Uswānī et déforme plusieurs faits... mais nous en fournit le tableau le plus détaillé. Selon lui, un traité conclu avec les Arabes aurait été bafoué par les Nubiens, qui pillèrent les villes égyptiennes de la première cataracte.

En 651 Abdallah Abou Sarh, qui avait succédé à Amr Ibn al-'As comme gouverneur d'Égypte, lança une seconde expédition contre Makouria avec une forte armée. Cette fois, il atteignit sans difficulté la capitale, Dongola, et en fit le siège en usant de catapultes, armes inconnues des Nubiens et détruisit en partie les églises. Selon al-Maqrizi, le roi de Makouria, qu’il nomme Qalidurut, serait alors entré en négociation. Mais d'autres auteurs décrivent une situation plus inégale: les archers nubiens, d'une précision diabolique, auraient infligé aux assaillants une pluie de flèches en visant particulièrement les yeux, ce qui leur valut dans la littérature médiévale arabe le surnom de «frappeurs de pupilles». Le traité de paix serait autant le résultat du nombre important de morts et de blessés dans le camp musulman, que de l'effet de leurs catapultes. Pour la première fois depuis leur sortie triomphale d'Arabie, les musulmans rencontrèrent une résistance inattendue en Nubie et durent composer avec leur ennemi.

Plutôt qu'un véritable traité, l'accord conclu entre eux était vraisemblablement un simple armistice accompagné d'un agrément comportant des dons réciproques. Il porte le nom de Baqt, qui est probablement un rare dérivé arabe du latin pactum, "pacte», mais désignait à cette époque simplement le tribut en esclaves qu'impliquait cet accord. Signé en l'an 31 de l'Hégire, soit en 652, il comporte quatre clauses. Premièrement, Nubiens et Arabes s'engagent à cesser leurs agressions mutuelles. Deuxièmement, les musulmans ont liberté de circuler en Nubie et les Nubiens en pays musulman, mais aucun des deux ne peut s'installer à demeure. Troisièmement, les Nubiens s'engagent à ne pas héberger d'esclaves fugitifs ou de transfuges musulmans, mais à les remettre aux autorités arabes. Quatrièmement, les Nubiens fourniront 360 esclaves en bonne santé chaque année aux musulmans, en échange de livraisons de céréales et de tissus. Al-Maqrizi ajoute une clause supplémentaire, la protection et l'entretien de la mosquée d'Old Dongola, mais il s'agit probablement d'une interpolation, car les fouilles n'ont jusqu'à présent mis au jour aucun édifice musulman construit dans la capitale à cette époque. 
Avec quelques périodes de vacuité, ce traité resta en vigueur jusqu'au $\mathrm{XIII}^{\mathrm{e}}$ siècle. Ce sont ainsi près de 100000 esclaves qui furent fournis aux autorités musulmanes. Cela n'alla pas toujours sans difficulté. On a par exemple retrouvé à Qasr Ibrim une lettre du gouverneur de l'Égypte se plaignant de la mauvaise qualité des esclaves fournis précédemment et du retard pris dans la livraison suivante. Il est assez probable que les rois de Makouria, à la fois pour honorer cette clause du Baqt et pour leurs propres besoins (notamment afin de renforcer leurs armées), lancèrent des raids réguliers contre les tribus du Kordofan et du Nil Bleu. Il semble que Dongola possédait des relais dans le Kordofan, qu'atteste un grand nombre d'emprunts lexicaux au nubien du Nil dans certaines tribus de la région, comme les Nyimang et les Ajang qui habitent aujourd'hui les Monts Nouba. Faute de fouilles archéologiques régulières dans le Kordofan, on ignore s'il s'agissait de simples postes coloniaux ou d'établissements plus conséquents.

\section{Le roi Merkourios, le "Nouveau Constantin"}

le Soudan

\section{6}

des origines

à la chute

du sultanat

Fung

Dans les années qui suivirent le raid des musulmans, les monuments détruits furent restaurés à Dongola et la cathédrale fut rebâtie en forme de basilique, coiffée d'un dôme et pavée de mosaïques. Bien que la menace venue du nord se fût atténuée avec l'établissement du Baqt, les travaux concernèrent aussi les fortifications de la ville, qui furent considérablement renforcées. Les relations avec Alodia étaient de surcroît toujours aussi tendues et, bien qu'il ne semble pas que des conflits importants aient éclaté entre les deux royaumes nubiens, il fallait parer à toute éventualité.

Aux rois Qalidurut et Zacharias succéda Merkourios (697-env.710), salué comme le "Nouveau Constantin". L'une de ses décisions les plus importantes fut, selon l'analyse de W.Godlewski, de rallier l'église monophysite, ce qui, après un siècle de fidélité au melkisme, s'explique sans doute par des raisons géopolitiques. La province de Nobadia et le royaume d'Alodia au sud étaient d'obédience monophysite. De plus, la conquête arabe de l'Égypte et de la Syrie rendait malaisés les contacts avec Constantinople. Enfin, en raison des guerres, il y avait presque un siècle que le pouvoir byzantin n'avait pas délégué de patriarche melkite à Alexandrie, alors que le patriarcat copte n'avait pas cessé d'être présent. De cette façon, Merkourios obtint enfin la nomination d'un siège métropolitain à Dongola, ce qui permettait d'ordonner des évêques sur place.

De nouvelles cathédrales furent alors bâties à Dongola et à Faras, capitale de la province de Nobadia. C'est d'ailleurs du règne de Merkourios que date la première mention d'un éparque de Nobadia (voir ci-dessus, p. 404), bien que l'institution ait peut-être existé auparavant. La cathédrale 


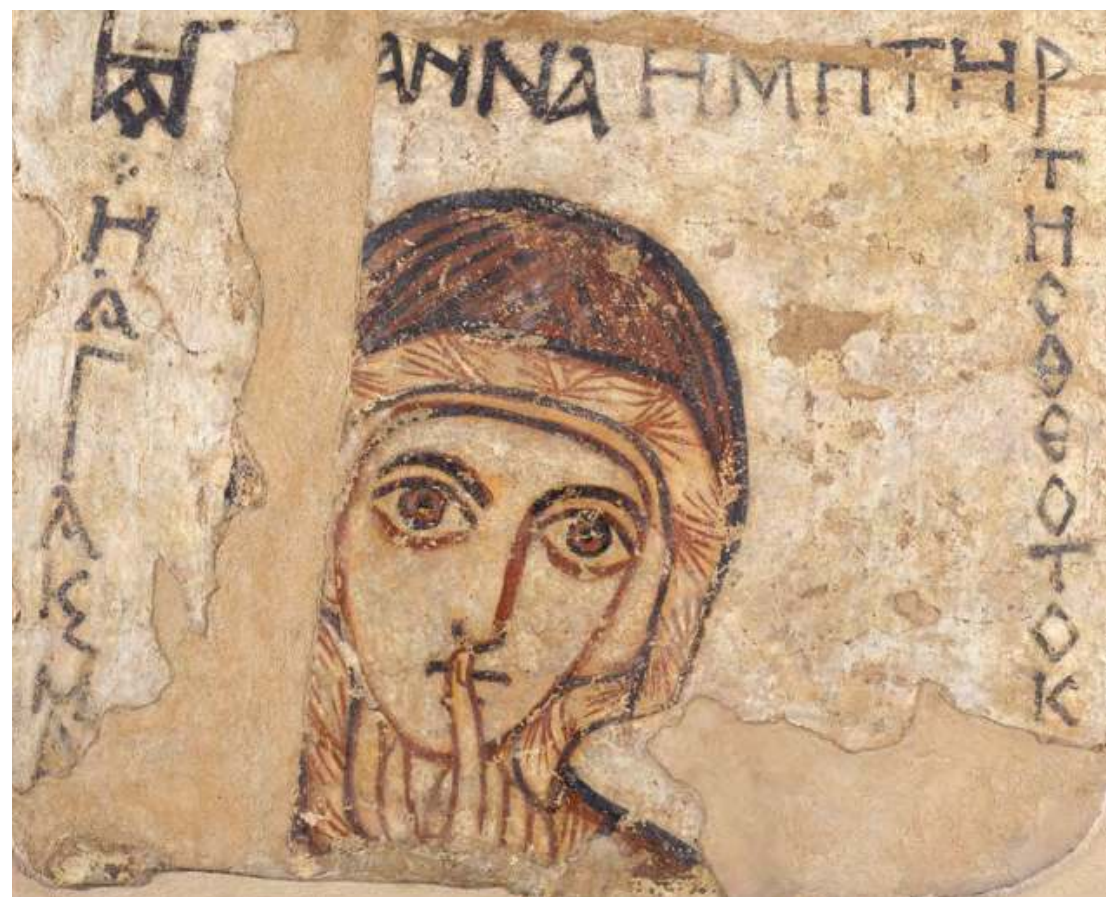

Sainte Anne, cathédrale de Faras, viII ${ }^{\mathrm{e}}$ siècle,

Muzeum Narodowe w Warszawie, nº 234058.

de Faras, qui fut enrichie au fur et à mesure des siècles, est emblématique de l'art nubien grâce ses peintures murales. Retrouvées par les archéologues polonais de 1961 à 1964, elles furent partagées entre le musée national de Khartoum, où elles remplissent presque la totalité du premier étage, et le musée de Varsovie. Datant de l'époque de la construction de la cathédrale, l'une des plus célèbres de ces peintures représente sainte Anne, la mère de la Vierge, le doigt sur la bouche, sans doute pour symboliser le mystère de la conception du Christ. Au nord de Faras, sur le site de Qasr el-Wizz, fut également bâti un grand monastère.

À la mort de Merkourios - selon la tradition rapportée par Jean Diacre l'Égyptien, chroniqueur copte d'Alexandrie — son fils Zacharias (nom très fréquent dans la dynastie makourite) préféra se retirer dans un monastère plutôt que de damner son âme par les compromissions et les machiavélismes liés au pouvoir royal. Paradoxalement, il garda la haute main sur la nomination de ses successeurs. Le premier, nommé Simon, était un de ses proches, homme de bien et très attaché à la doctrine monophysite adoptée par Merkourios. Mais il mourut assez vite et Zacharias le remplaça par un certain Abraham, un choix moins heureux. En effet, des querelles éclatèrent assez vite entre lui et l'évêque métropolitain de Dongola. Le nouveau roi porta l'affaire devant le patriarche d'Alexandrie 
qui, bien que persuadé du bon droit de l'évêque, consentit par réalisme politique à l'éloigner de Dongola et à nommer un remplaçant. Zacharias, qui apparemment n'était retiré du monde qu'en théorie, réagit en exilant Abraham et nomma un nouveau roi en la personne d'un certain Markos. Mais celui-ci ne régna que six mois, avant d'être tué dans la cathédrale de Dongola par des sbires à la solde d'Abraham.

\section{Le règne de Cyriaque, le "grand roi "}

le Soudan

\section{8}

des origines

à la chute

du sultanat

Fung

Le roi Cyriaque (env. 746-770) accède au trône de Makouria en des temps particulièrement agités, aussi bien en Nubie qu'en Égypte. Son prédécesseur, Markos, a été assassiné, et il semble que Zacharias, le prince faiseur de rois, était déjà décédé. En Égypte, le gouverneur Abd el-Malik, en désaccord avec le patriarche copte d'Alexandrie, Michel Irer, l'avait fait emprisonner. Le roi Cyriaque envoya alors l'éparque de Nobadia auprès du gouverneur pour exiger la libération du patriarche. Mais Abd el-Malik fit également jeter l'éparque en prison.

Furieux, Cyriaque convoqua une armée qui, selon Jean Diacre, ne comportait pas moins de cent mile cavaliers et autant de méharistes, chiffre évidemment très exagéré, et, en 749-750, il commença à prendre et piller les villes de Haute-Égypte. Incapable de faire face à une telle invasion, Abd el-Malik relâcha l'éparque puis le patriarche. Le roi Cyriaque, après avoir amassé un considérable butin, retourna à Dongola sans avoir eu besoin de livrer bataille. Par la suite, les relations entre Makouria et les Arabes ne vont pas cesser de s'améliorer.

En 750, le dernier calife omeyyade, Marwan II, fut vaincu par une rébellion qui installa une nouvelle dynastie à Bagdad, les Abbassides. Marwan s'enfuit en Égypte, où il fut rattrapé et mis à mort. Deux de ses fils cherchèrent asile en Nubie, mais, conformément à une des clauses du Baqt, le traité entre Arabes et Makourites, Cyriaque refusa de les accueillir et les fit accompagner vers la mer Rouge. Le prestige du roi de Makouria auprès des autorités égyptiennes, tant coptes que musulmanes, ressort particulièrement par le titre arabe de "grand roi " (al-malik al-azim) que lui confère Jean Diacre.

Avec Alodia également les tensions d'hier sont en passe d'être résolues. L'adoption du monophysisme sous Merkourios a probablement contribué largement à la détente. Bien que l'on ne possède pas de témoignage historique de ce rapprochement entre les deux royaumes, des indices archéologiques vont dans ce sens. L'architecture alodienne subit alors une nette influence makourite: la cathédrale de Soba est apparemment rebâtie sur le modèle de celles de Dongola et de Faras. D'autre part, la poterie 
caractéristique de Soba, dite Alwa ware, laisse place à des importations massives de Makouria, qui montrent l'importance des relations commerciales nouvelles entre les deux États.

\section{L’âge d'or de la Nubie chrétienne du IXe au XIIIe siècle}

Les quatre siècles qui suivent constituent la période la plus brillante des royaumes nubiens, quoique nos sources continuent à être rares pour Alodia. Au début du $\mathrm{IX}^{\mathrm{e}}$ siècle, il fallut au royaume de Makouria solder auprès de l'Égypte musulmane un lourd contentieux qui menaçait la paix fragile entre les deux pays. Les livraisons d'esclaves prévues dans le Baqt, le traité de non-agression, n’avaient pas été effectuées depuis quatorze ans, l'Empire abbasside étant déchiré par les guerres de succession entre les fils du calife Haroun al-Rachid. Le régent Zacharias, qui régnait alors à Dongola, fut sommé par les Arabes de régler la dette, mais en était bien incapable: il aurait fallu rassembler immédiatement plus de 5000 esclaves correspondant aux critères rigoureux du Baqt, c'est-à-dire des hommes et des femmes jeunes et sans défauts physiques. En 836 il décida alors de déléguer à Bagdad son fils, le roi Georges Ir, âgé de vingt ans, auprès du calife abbasside Al-Mutasim, afin de négocier directement avec lui.

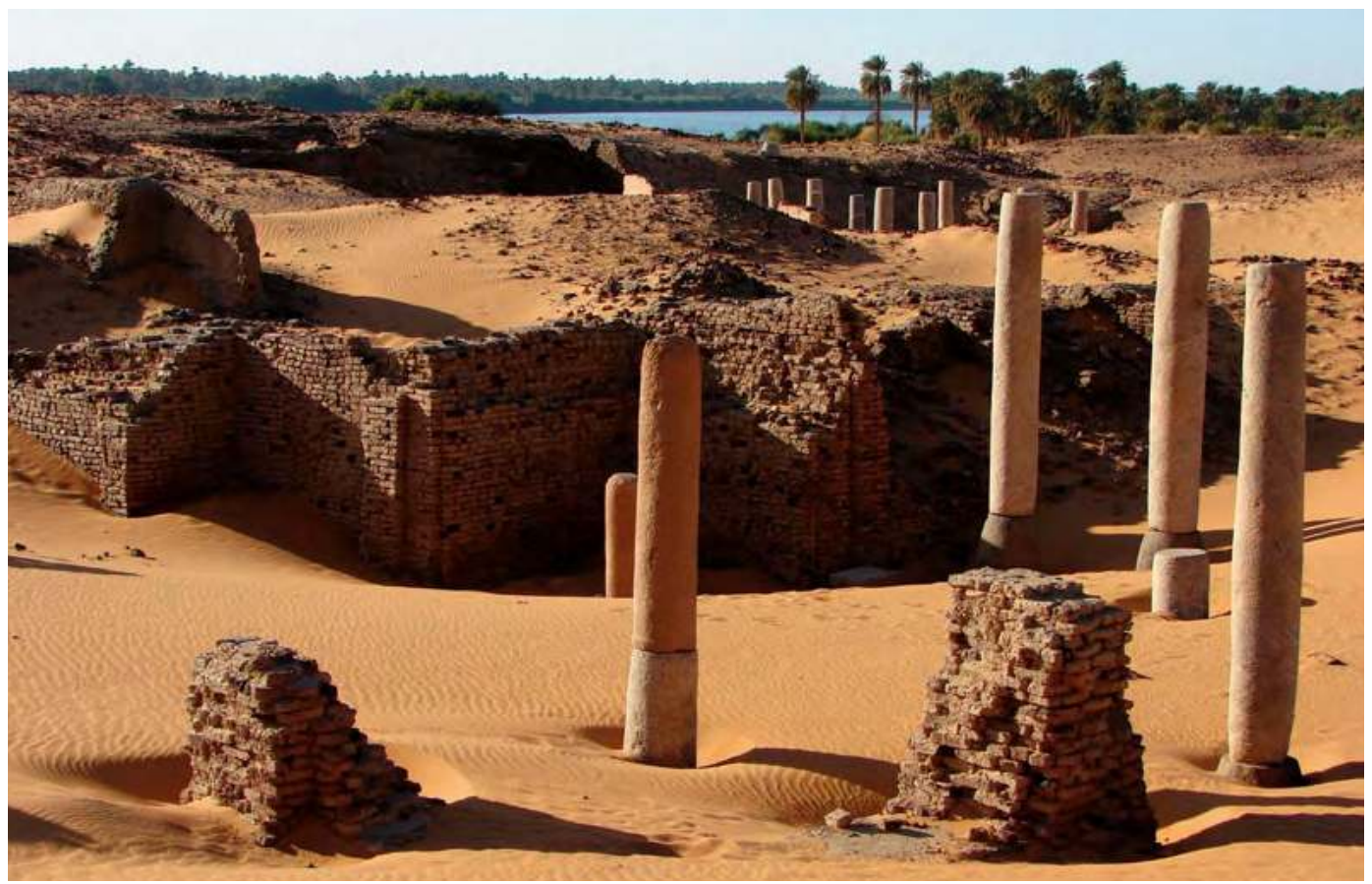

Old Dongola, vestiges de l'église cruciforme, Ix' siècle. 
Cette ambassade était tout à fait extraordinaire en raison de la qualité de l'envoyé: le jeune souverain en personne, qui devrait affronter les mille dangers d'un si long et difficile voyage. Mais s'il en réchappait, son arrivée à Bagdad serait une insigne marque d'honneur de Makouria envers le calife et les musulmans. C'est bien ainsi qu'elle fut interprétée. Après une étape en Égypte, le roi Georges et son escorte, rutilants d'or et chargés de présents, furent accueillis avec curiosité et bienveillance par Al-Mutasim. Non seulement il remit leur dette aux Nubiens, mais il décida que le Baqt ne serait versé que tous les trois ans et renvoya après plusieurs mois le roi Georges dans son pays, muni de somptueux cadeaux. Le pari du régent Zacharias était gagné au-delà de toute espérance.

Ce nouveau départ pour le royaume fut marqué par l'édification d'une nouvelle cathédrale à Dongola, qui surpassait toutes les constructions précédentes. Sur le site de la basilique fut érigé un bâtiment grandiose de plan cruciforme, coiffé d'une coupole qui atteignait $28 \mathrm{~m}$ de hauteur. C'est peu après que fut lancée la construction d'un palais royal ou plutôt d'une salle d'audience pour recevoir les ambassades. Ce monument emblématique d'Old Dongola a été préservé jusqu'à nos jours grâce à sa conversion en mosquée au XIv ${ }^{e}$ siècle. Il s'élève sur un escarpement rocheux au-dessus de la citadelle, si bien qu'il est visible depuis des kilomètres, y compris de la rive ouest du Nil. De forme quadrangulaire, doté de murs formidables, il comporte deux étages auxquels on accède par un escalier monumental. La salle d'audience proprement dite, située au sommet, comprend un dais encadré de colonnes de granit décorées où se tenait le trône du souverain. Elle est percée de larges fenêtres qui offrent une vue grandiose sur la ville et les environs jusqu'à la boucle du fleuve au sud.

à la chute

du sultanat

Fung
Le royaume de Makouria durant ces siècles d'or se couvre d'églises et de monastères. La technique nubienne des peintures murales religieuses connait alors son apogée et constitue un des sommets de l'art pictural chrétien, surpassant de loin ce que l'on pouvait trouver en Égypte. Il ne s'agit pas de fresques à proprement parler, puisque le support est sec quand le pigment est appliqué, mais de peintures a tempera, comme les icônes. Les plus belles œuvres retrouvées sur les murs de la cathédrale de Faras et actuellement conservées au musée de Khartoum en offrent une splendide illustration. Ainsi de la scène montrant les trois jeunes Hébreux dans la fournaise, un épisode tiré du Livre de Daniel, qui évoque le sauvetage par un archange des trois jeunes gens que le roi de Babylone Nabuchodonosor avait fait jeter dans une fosse emplie de feu. Elle date du XI ${ }^{e}$ siècle, où des gammes chaudes de rouge et de jaune ont remplacé les teintes sévères des siècles précédents. Un siècle encore, et c'est toute la palette des couleurs possibles qui apparait dans la plus connue et la plus grande des peintures 

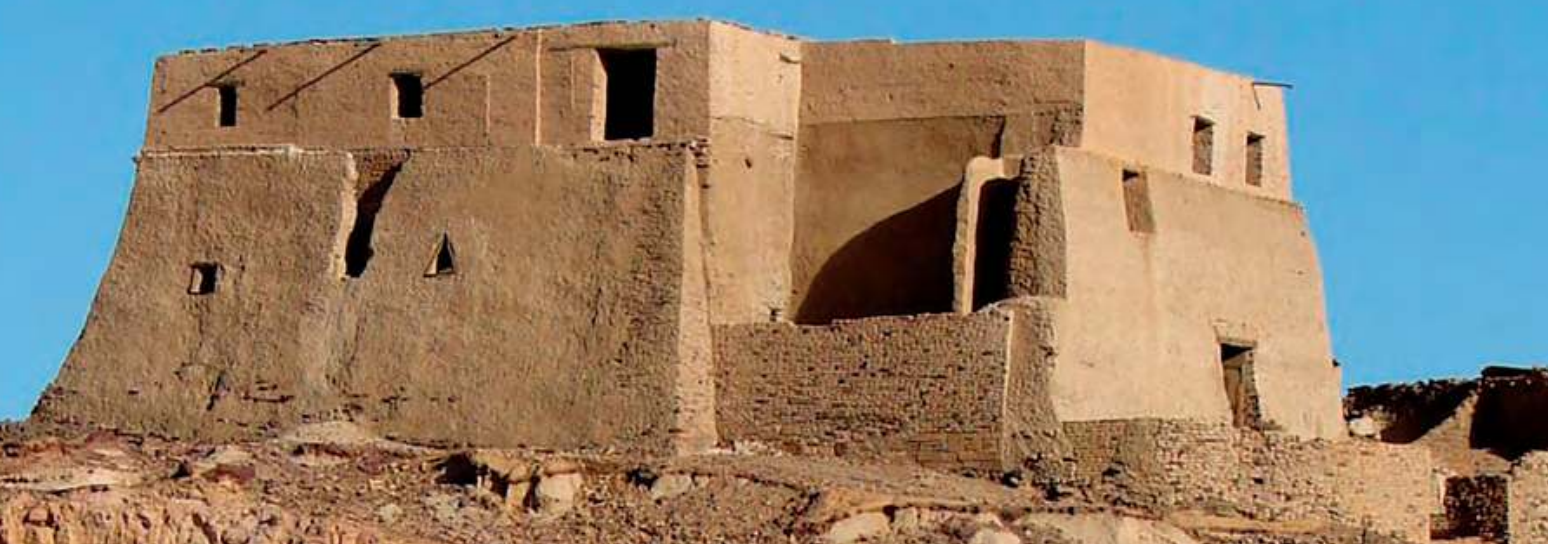

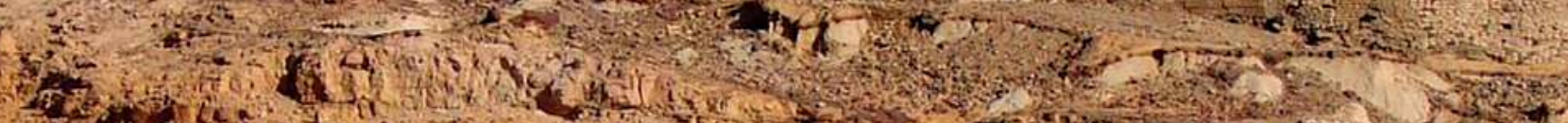

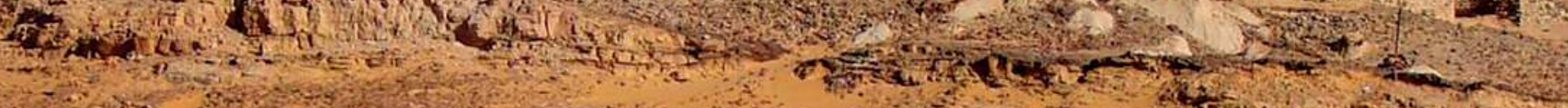

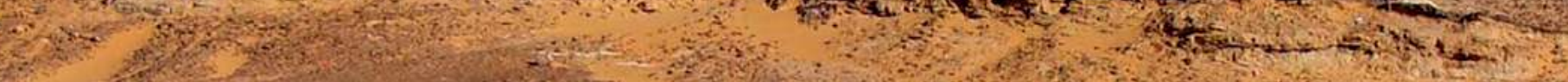

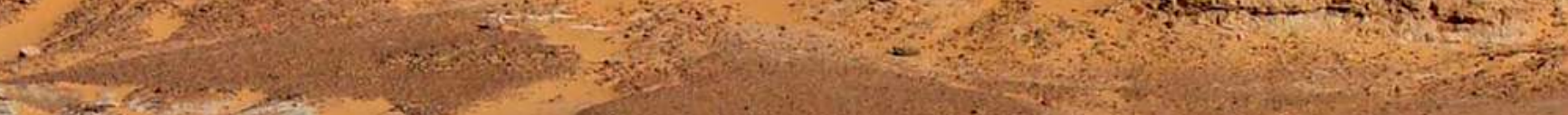

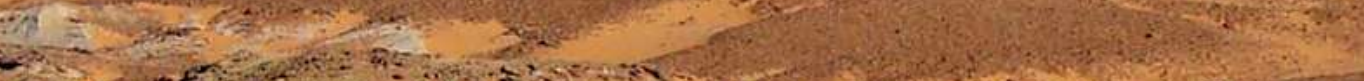

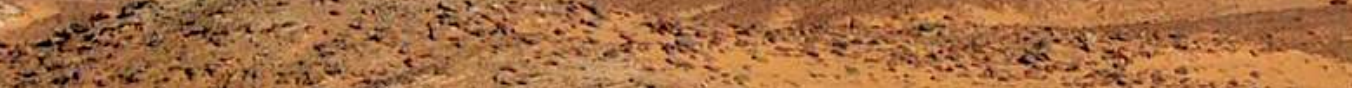

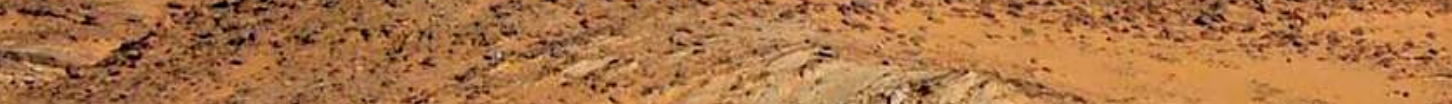

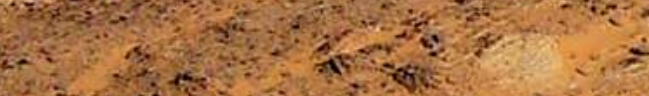

$2 x^{2}+2+15$

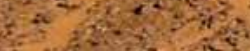

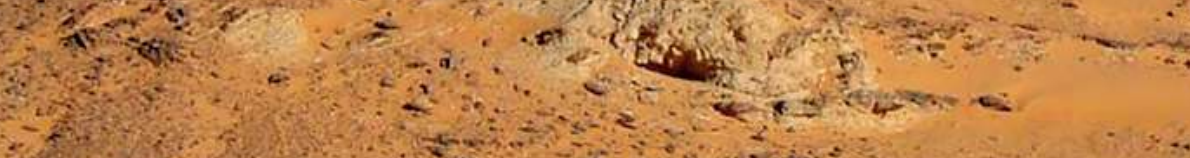

(4)

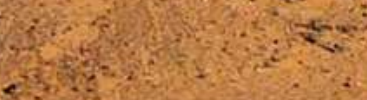

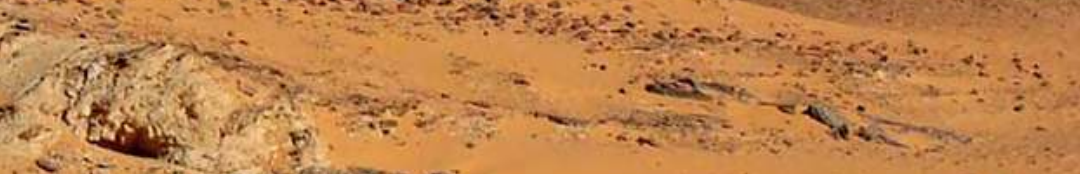

H. 4.9

i.

Old Dongola, salle d'audience des rois dé Makouria. 


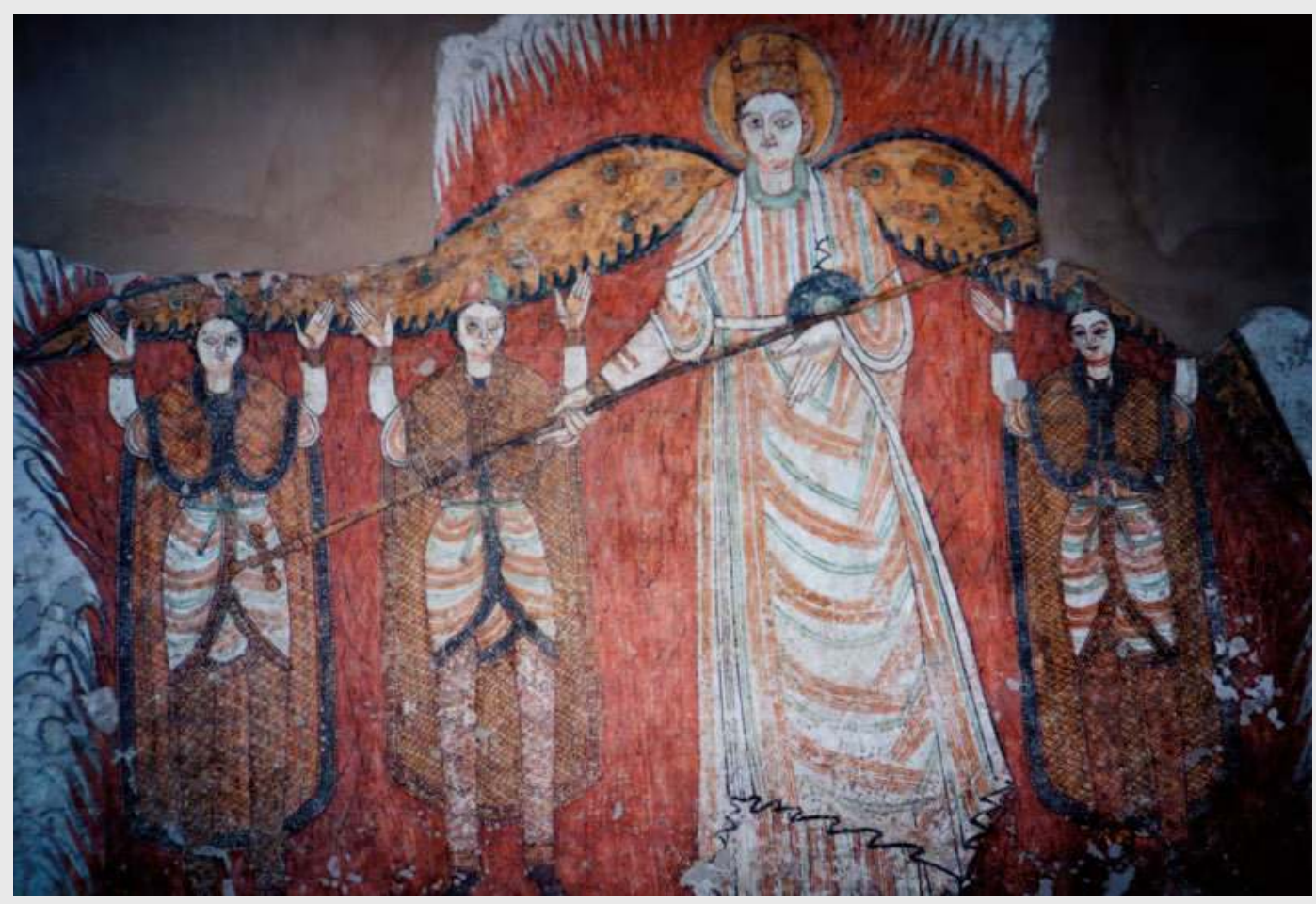

le Soudan

Les jeunes Hébreux dans la fournaise, cathédrale de Faras, $\mathrm{XI}^{\mathrm{e}}$ siècle, musée national, Khartoum.

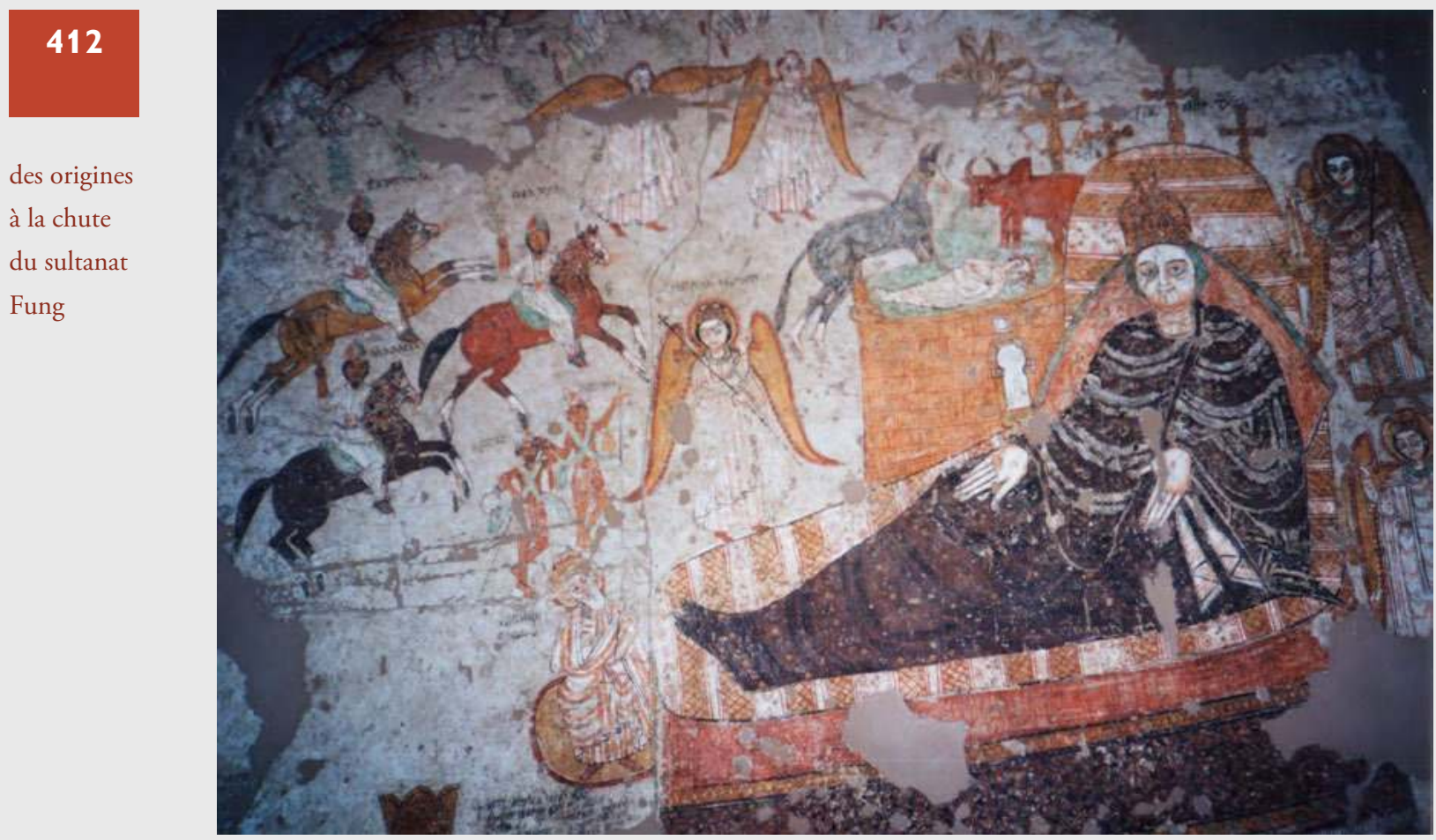

La Nativité, cathédrale de Faras, XII ${ }^{e}$ siècle, musée national, Khartoum. 
de Faras, la Nativité, qui ornait le mur oriental de la cathédrale. Très éloignée du dénuement évoqué par l'Évangéliste, la scène donne une version quasi royale de la naissance du Christ. Allongée sur un riche sofa et vêtue d'une robe sombre rehaussée de broderies, une immense Vierge au teint blanc fait face au spectateur. L'enfant Jésus est quant à lui placé dans une mangeoire en forme d'église. Le ciel est empli des grandes ailes des anges et des archanges. Sur la gauche arrivent en riche arroi les trois rois mages à cheval, côtoyant deux petits bergers presque nus, à la peau sombre, qui dansent d'allégresse. Sous la scène est représenté un roi nubien, dédicateur $\mathrm{du}$ tableau. Les fouilles récentes d'Old Dongola par les équipes polonaises, notamment celles du monastère Saint-Antoine et de l'église de Banganarti, à quelques kilomètres au sud de la capitale, ont révélé des peintures qui égalaient en splendeur et surpassaient parfois en technique celles de Faras. Mais leur état de conservation moins bon n'a pas permis de les déposer et elles ne peuvent être vues qu' in situ.

L'architecture militaire est aussi bien représentée dans les royaumes nubiens, particulièrement en Basse et Moyenne Nubie où furent bâties nombre de forteresses afin de prévenir les raids des musulmans depuis le nord qui, en dépit du Baqt, n'avaient jamais totalement cessé, mais étaient peu intenses. Cette longue période de paix armée permit aux royaumes nubiens de développer une économie prospère. $S^{\prime} y$ ajoutaient des conditions climatiques plutôt favorables, avec des pluies et des crues importantes jusqu'au XII siècle. L'agriculture bénéficia de la large extension d'une technique d'irrigation connue depuis l'antiquité tardive en Égypte mais qui ne se diffusa en Nubie que durant la période postméroïtique, la saqieh. Ce système de grandes roues en bois solidaires, entraîné par un animal, permettait de puiser l'eau en contrebas par un jeu de godets qui la déversaient dans un canal. Il était particulièrement utile au Soudan où le lit du Nil est généralement trop escarpé pour que l'inondation annuelle se répande naturellement dans les champs. Les saqiehs étaient très souvent la propriété des monastères et des églises qui les mettaient à la disposition des paysans contre une rémunération en nature prélevée sur la récolte.

Un rapport détaillé de l'organisation administrative et de l'économie des royaumes nubiens nous est donné par le géographe égyptien Ibn Sulaym al-Uswani au Xe siècle. Originaire d'Assouan, comme son nom l'indique, il a voyagé dans le royaume de Makouria et bénéficié de l'amitié du roi, auprès duquel il avait été envoyé en ambassade par le calife fatimide d'Égypte. Mais il semble qu'il n'ait pas poussé son exploration jusqu'au territoire d'Alodia et se soit, à son propos, contenté de sources orales. Son manuscrit est perdu, mais il est en partie cité par des écrivains plus tardifs et principalement son compatriote al-Maqrizi, au début du Xve siècle. 


\section{La description de la Nubie d'après al-Uswani}

$\mathrm{X}^{\mathrm{e}}$ siècle; cité par al-Maqrizi. D’après la traduction anglaise

de G. Vantini, Oriental Sources concerning Nubia,

Heidelberg-Varsovie, 1975. Intertitres ajoutés

\section{la frontière avec l'Égypte}

Le premier village des Nubiens est al-Qasr, à cinq milles d'Assouan. La dernière place forte des musulmans est une île appelée Bilaq (Philae), à un mille du village nubien qui est situé sur la rive nubienne du fleuve. Depuis Assouan jusqu'à cet endroit, le Nil comporte de grands rapides. Les bateaux n'y peuvent passer qu'avec l'habile assistance de pêcheurs locaux qui connaissent bien les lieux, car les rochers sont abrupts et le fleuve divisé en nombreux chenaux. Le grondement de la cataracte s'entend de très loin. Dans ce village, il y a une garnison armée et une porte menant au pays des Nubiens. Entre ce village et la première cataracte du pays nubien (la deuxième cataracte du Nil) se trouvent dix stations. Les musulmans qui vivent dans cette région sont libres de posséder des terres dans le voisinage et de se livrer au commerce en amont. Il y a quelques habitants musulmans mais aucun ne parle arabe. Cette région est étroite et accidentée, entourée de montagnes et limitée aux berges du Nil, le long duquel les villages se succèdent avec leurs palmiers et leurs arbres à gomme.

\section{la Basse-Nubie}

des origines

à la chute

du sultanat

Fung

La partie de cette contrée située en amont est plus large qu'en aval et possède des vignes. Le Nil n'inonde pas les champs en raison de la forte déclivité du sol. La largeur de la surface cultivée est deux ou trois feddans (8o à 120 ares) et elle est irriguée par des saqiehs [roues à eau] actionnées par des bœufs. Les habitants y font pousser un peu de blé mais surtout de l'orge et du seigle. Comme la bande cultivable est étroite, ils y plantent en continu sans période de jachère. En été, après avoir fertilisé le sol avec du fumier et de la terre rapportée, ils l'ensemencent de sorgho et de millet, de sésame et de fèves.

Dans cette région est située la cité de Bujarash (Faras), la capitale de Maris (Nobadia), ainsi que deux forteresses, dont celle de [Qasr] Ibrim. Il y a aussi un port appelé Adwa [...] et les ruines remarquables d'un temple païen. Cette région est administrée par un gouverneur appelé «le Seigneur de la Montagne» (éparque de Nobadia), qui représente le grand Seigneur des Nubiens (roi de Makouria). Il compte parmi leurs gouverneurs du plus haut rang. Comme cette région est limitrophe de la terre d'Islam, toute personne qui vient du pays des musulmans doit s'adresser à lui, tant pour s'identifier 
que pour apporter un cadeau destiné à lui ou à son seigneur. Il reçoit tout le monde et leur offre des esclaves mais ne permet à personne, musulman ou non, de continuer sa route pour rendre visite à son seigneur.

\section{le Batn-el-Hajjar}

Sur la première cataracte du pays des Nubiens (la deuxième cataracte du Nil), il y a un village appelé Baqwa qui est un terminal pour les bateaux des Nubiens qui remontent le fleuve depuis al-Qasr, à la frontière de leur pays. Les embarcations ne peuvent aller plus loin. Nul, musulman ou non, n'a le droit de continuer en amont au-delà de ce point, sauf permission expresse du Seigneur de la Montagne. Entre ce port et le Maqs Supérieur (la Moyenne Nubie), il y a six étapes entourées de rapides. C'est la pire partie de cette région que j'ai vue, car le chenal est étroit, très difficile pour la navigation, empli de rapides et d'obstacles rocheux et par endroits guère plus large que cinquante coudées. Le paysage de chaque côté du fleuve est coupé de passes resserrées, de sommets élevés et de cols montagneux si étroits que ni un cavalier ni un voyageur à pied mal équipé ne peuvent les franchir. Les rives occidentale et orientale sont toutes deux couvertes de sable. Les montagnes sont pour les habitants autant de forteresses où ils peuvent se réfugier. Sur quelques îles, il y a des palmiers et des plantations de peu de valeur. La nourriture de base est le poisson. Ils utilisent de la graisse de poisson pour s'enduire la peau. Ces îles dépendent de Maris et sont sous l'autorité du Seigneur de la Montagne.

\section{la Moyenne-Nubie}

Le gouverneur de la garnison qui est dans le Maqs Supérieur (Moyenne-Nubie) est désigné par leur seigneur. Il exerce un contrôle très strict sur eux (les Nubiens), si strict que même l'homme le plus élevé, quand il vient à passer, est arrêté par n'importe quel soldat de la garnison qui feint de le fouiller et qui peut faire de même aux fils du roi, à ses vizirs ou qui que ce soit d'autre.

Ici le dinar et le dirham ne sont d'aucun usage parce que les habitants n'utilisent pas de monnaie dans leurs transactions, à part avec les musulmans au-delà de la cataracte. Ils n'achètent ni ne vendent pour de la monnaie mais effectuent ces opérations en troquant contre des esclaves, du bétail, des chameaux, des outils de fer ou du grain.

Personne ne peut remonter au-delà de ce lieu sauf permission expresse du roi. Celui, quel qu'il soit, qui transgresse cette interdiction est passible de la peine de mort. Grâce à ces précautions, tout ce qui se passe [dans le royaume] est tenu secret, si bien que leur armée peut attaquer un pays ou mener une expédition dans le désert sans que personne n'en soit averti. [...] 
le Soudan

\section{6}

des origines

à la chute

du sultanat

Fung
En amont de cette garnison se trouve un village appelé Say (l'île de Saï) qui est situé sur une cataracte. C'est l'un des chefs-lieux de leur pays et le siège d'un évêque. Il y a un temple païen en ruine. Plus en amont se trouve la région de Saqluda (le Sukkot) qui signifie les «sept gouverneurs» (en fait "les sept districts»). C'est une terre très semblable à la région qui borde le pays des musulmans, tour à tour large ou étroite, avec des palmiers, des vignes, des arbres à gomme et autres plantations. Il y a quelques champs de coton qui produisent du coton brut et il y a aussi quelques oliviers. Le gouverneur de cette région est directement nommé par le roi et il commande à d'autres gouverneurs qui exercent une autorité (locale). Ici se trouve une forteresse nommée Astanun qui marque le début de la troisième cataracte, la plus difficile à traverser, parce qu'il y a une montagne qui empiète sur le fleuve d'est en ouest et que les eaux s'engouffrent sur trois passages, qui peuvent être limités à deux en période d'étiage. Elle produit un formidable grondement mais offre une belle vue parce que les eaux se déversent depuis le haut de la montagne. Au sud, le lit du fleuve est plein de rochers qui en obstruent le milieu, sur une distance de trois jours de navigation, jusqu'au village de Bastu qui est le dernier village de Maris et marque le début du territoire de Muqurra (Makouria proprement dite). Entre cet endroit et la frontière des musulmans, la langue des habitants est le marisi (le nobiin), le Maris étant l'extrémité (nord) des possessions de leur roi.

\section{le bassin de Kerma}

Il y a une contrée nommée Baqun, qui signifie "merveille», appelée ainsi à cause de sa beauté. Je n'ai jamais vu une région plus large sur le Nil: j'estime que la largeur de [la vallée du] Nil, d'est en ouest, est de cinq jours de marche. Des îles divisent le fleuve en plusieurs bras qui les entourent et coulent au milieu d'une plaine, le long d'un chapelet ininterrompu de villages et de beaux édifices avec des pigeonniers, du bétail et des chameaux. L'essentiel de la nourriture dont leur capitale est ravitaillée provient de cette contrée. [...] Leur roi a sa villégiature préférée dans cette région. Je l'ai accompagné (dit al-Uswani) à plusieurs de ces occasions et nous sommes passés par des chenaux étroits sous le couvert des arbres des deux rives. Les crocodiles dans ce pays ne sont pas dangereux: j'ai vu des gens traverser ces chenaux à la nage.

\section{la région de Kawa et Old Dongola}

En amont se trouve la région de Safad Baal, relativement étroite, semblable à celle qui jouxte la frontière de leur pays, à la différence près qu'à Safad Baal il y a de belles îles et qu'à moins de deux journées de voyage se trouvent près de trente villages avec de beaux édifices, églises 
et monastères, de nombreuses palmeraies, vignes, jardins, champs cultivés et larges pâtures où l'on peut voir des chamelles et de très beaux dromadaires pour la reproduction. Leur roi vient souvent là parce que la frontière sud de cette région est limitrophe de Dongola (Old Dongola), la capitale. De la ville de Dongola, capitale du pays, à Assouan, il y a une distance de cinquante jours de voyage. (al-Uswani en donne une description et ajoute ceci:) Ils couvrent leurs maisons avec du bois d'acacia et de $s a j$, qui est charrié par le Nil lors de la crue et leur arrive en planches avec des gravures, sans que personne ne sache d'où elles viennent. J'y ai vu moi-même des signes très étranges.

\section{de la quatrième à la cinquième cataracte}

La distance qui sépare Dongola et le début du pays d'Alwa (Alodia) est supérieure à celle qui sépare Dongola d'Assouan. Dans cette contrée, il y a des villages petits et grands, des îles, du bétail, des palmeraies, [...] des champs cultivés et des vignes, en quantité bien plus grande que ce que l'on voit du côté [du royaume] qui jouxte le pays des musulmans. Dans cette région s'étendent des îles dont la longueur équivaut à plusieurs jours de marche et où il y a des montagnes, des bêtes sauvages et des lions, ainsi que des étendues de désert où le voyageur doit craindre de cheminer sans réserve d'eau. Depuis ces contrées, le cours du Nil tourne vers l'est et l'ouest sur de longues distances équivalentes à plusieurs jours de marche, et ce jusqu'à la plaine où la boucle du Nil atteint la mine appelée al-Shanka. [...] Les hippopotames sont nombreux dans les environs. À cet endroit commence la piste qui mène à Souakin, Badi, Dahlak et les îles de la mer Rouge. C'est par là que passèrent les Omeyyades (les fils de Marwan II) qui avaient fui chez les Nubiens pour échapper à la mort. Dans cette région vivent aussi un certain nombre de Bedjas qu'on appelle les Zanafij. Ils ont émigré en Nubie il y a longtemps et se sont installés là. Ils mènent tous une vie pastorale et conservent leur propre langue sans se mêler aux Nubiens ni se sédentariser dans les villages. Ils dépendent d'un administrateur nommé par le roi de Nubie (Makouria). [...]

\section{la frontière d'Alodia et l'Atbara}

La frontière du pays d'Alwa (Alodia) se situe en un lieu appelé al-Abwab («les Portes» en arabe), où il y a quelques villages sur la rive est du Nil. Cette région a un administrateur qui est aux ordres du seigneur d'Alwa et porte le nom de wahwah. À partir de là, le Nil se divise en sept bras, dont l'un vient de l'est, a des eaux boueuses mais s'assèche complètement en été, si bien que les gens peuvent installer leurs campements sur son lit. Lorsque vient la saison des crues, l'eau surgit de son lit et y forme des mares, puis les 
pluies et les écoulements se produisent dans toute la région et le niveau de l'eau monte. On dit aussi que la source de cette rivière s'écoule depuis une montagne. [...]

\section{Soba, capitale d'Alodia}

Suyya (faute de copiste pour Soba) est la capitale d'Alwa, située à l'est de la grande île entre les deux fleuves, le [Nil] Blanc et le Vert (Nil Bleu), à son extrémité nord, près du confluent [...]. La ville possède de beaux bâtiments et de grands monastères, des églises richement parées d'or et de jardins. Il y a également un large faubourg où vivent de nombreux musulmans. Le roi d'Alwa est plus puissant que le roi de Makouria, il possède une armée plus importante et plus de chevaux que le Makourite. Son pays est plus fertile et plus étendu, mais les palmeraies et les vignobles y sont moins nombreux. La céréale la plus répandue est le sorgho blanc qui ressemble à du riz. Ils en tirent leur pain et leur bière. Ils ont de la viande en abondance grâce à leur nombreux bétail et aux vastes plaines où il peut paître, si larges qu'il faut plusieurs jours pour atteindre les montagnes. Ils ont d'excellents chevaux et des dromadaires de couleur fauve, de pure race arabe. Leur religion est le christianisme d'obédience jacobite (copte); leurs évêques dépendent du patriarche d'Alexandrie comme les Nubiens (Makourites). Leurs livres sont en grec et ils les traduisent dans leur propre langue. Ils sont moins intelligents que les Nubiens. Leur roi peut réduire en esclavage à son gré n'importe lequel de ses sujets, coupable d'un crime ou non, et ils ne s'y opposent pas mais se prosternent devant lui. Ils ne se révoltent pas contre cet ordre, si injuste soit-il, mais crient bien fort: «Vive le roi! Que son ordre soit exécuté!» Sa couronne est en or. On trouve de 


\section{Le déclin et la chute des royaumes nubiens $\mathrm{XI}\left\|^{\mathrm{e}}-\mathrm{XV}\right\|^{\mathrm{e}}$ siècles}

En 1250, le sultanat ayyoubide d'Égypte, qui depuis Saladin gouvernait le pays, fut remplacé par la dynastie mamelouke. À de multiples occasions dans le passé où le pouvoir avait basculé en Égypte, comme lors des invasions macédonienne ou romaine, les souverains soudanais s'étaient enhardis et avaient tenté de pousser leurs pions vers le territoire de leur voisin. Semblablement, le nouveau roi de Makouria, David, qui avait déposé son oncle Shékanda peu auparavant, se lança dans une expédition hasardeuse en 1275 en attaquant le port d'Aidhab sur la mer Rouge, jusqu'alors aux mains des Égyptiens. Puis, traversant le désert Arabique à marche forcée, il dirigea ses troupes sur la ville d'Assouan. La réplique du sultan mamelouk Baybars ne se fit pas attendre. Son armée envahit la Nubie et poussa jusqu’à Dongola en 1276, où elle rétablit sur le trône le roi Shékanda, lui imposant toutefois un lourd tribut et la cession de provinces entières au pouvoir mamelouk.

Une dizaine d'années plus tard, pour une raison que les chroniqueurs arabes n'expliquent pas clairement, Makouria, alors sous le règne d'un nouveau roi, Shémamoun, fut à nouveau envahie et Dongola fut mise à sac en 1288. Le souverain makourite, déposé par les musulmans, revint cependant au pouvoir immédiatement après leur départ, obligeant le sultan mamelouk à organiser une seconde expédition contre Shémamoun, qui se conclut, comme la précédente, par son retour sur le trône en 1290, une fois l'armée musulmane revenue au Caire. Il s'engagea à payer le Baqt annuellement et bénéficia de la clémence des Mamelouks, fatigués de ces expéditions répétées et occupés par les guerres de succession à la mort du sultan Qalâwun, la même année.

Les années 1315 à 1326 connurent une alternance, au gré des batailles où intervinrent sans cesse les armées mameloukes, entre Kérenbès, le dernier roi chrétien de Makouria, pourtant soutenu par Le Caire, et son neveu musulman Kanz al-Dawla Abou Abdallah Mohammed. La famille royale de Dongola comportait en effet de plus en plus de membres acquis à l'islam. L'historien arabe Ibn Khaldoun, qui écrit peu après les faits, explique ce fait par une stratégie délibérée de la part de chefs nomades islamisés (essentiellement des Bedjas et des Arabes Juhayna) qui auraient épousé des princesses nubiennes durant l'affaiblissement du royaume, monnayant par ces alliances leur support militaire. Selon le droit islamique, les enfants de telles unions étaient musulmans, mais, selon les coutumes nubiennes, ils héritaient du pouvoir royal, de type matrilinéaire, qui se transmettait par les sœurs du souverain, d'oncle maternel à neveu. 
Ces mariages auraient inévitablement entraîné une islamisation de la dynastie. Tel était le cas d'Abou Abdallah Mohammed, dont la lignée paternelle remontait à un prince arabo-bedja auquel les califes fatimides avaient accordé au XI ${ }^{\mathrm{e}}$ siècle une principauté autour d'Assouan et le titre arabe de «Kanz al-Dawla», signifiant "Trésor de l'État».

En 1317, sous le règne du Kanz al-Dawla, le palais d'audience des rois de Dongola fut transformé en mosquée, la plus ancienne du Soudan encore debout aujourd'hui, bien que désacralisée en 1969 et devenue propriété du service des Antiquités. À la même époque, selon Ibn Khaldoun, le Baqt fut aboli puisque Makouria était devenue, au moins par son souverain, une terre d'Islam. Toutefois, le Kanz al-Dawla ne termina pas sa vie sur le trône de Dongola. Déposé, il gagna Assouan, le fief de ses pères, avec une grande partie de sa cour et y fonda une colonie de langue nubienne. C'est de ces colons que descendent les Nubiens Kunuz (d'après le nom de Kanz) qui constituent aujourd'hui l'ethnie nubienne principale d'Égypte et se sont transmis une forme particulière de la langue de Dongola.

En 1364, devant les assauts répétés des tribus arabisées, la capitale de Makouria, Old Dongola, fut abandonnée et la région, évacuée. Une partie des habitants fondèrent à plus de cent kilomètres au nord, sur la rive gauche du Nil, une nouvelle ville à laquelle ils donnèrent le même nom, Dongola, et qui est aujourd'hui la capitale de l'État du Nord dans le Soudan fédéral. La cour royale se retira en Basse-Nubie, à Daw (actuel Gébel Adda), tandis que l'éparque de Nobadia était établi un peu au nord, à Qasr Ibrim. C'est au cours des fouilles de ce site dans les années 1970 que fut retrouvée, parmi un nombre considérable d'écrits d'époques variées (que nous avons

des origines

à la chute

du sultanat

Fung évoqués dans le chapitre précédent), la correspondance en vieux-nubien des éparques entre le $\mathrm{XIV}^{\mathrm{e}}$ et le $\mathrm{XV}^{\mathrm{e}}$ siècle. Complétée par quelques documents de la région, elle montrait que le christianisme était encore bien vivant en Nubie et qu'une lignée de rois chrétiens avait perpétué le royaume de Makouria au nord. Ces monarques sont appelés en vieux-nubien «roi du Dotawo». On sait désormais que "Dotawo» était le nom nubien de Makouria, jamais attesté par ailleurs (le terme «Makouria» n'apparait en effet que dans les textes en grec) et non, comme on l'a longtemps cru, une principauté locale qu’aurait reprise les souverains émigrés de Dongola. Le dernier roi connu est Joël, vers 1484. Puis on perd toute trace d'un pouvoir nubien centralisé, jusqu'à ce que les troupes ottomanes, vers 1560 , investissent le nord du pays et $y$ construisent des forteresses.

La chute du royaume d'Alodia, comme en général l'histoire de ce pays, est beaucoup moins documentée que celle de son voisin du nord. Les sources sont réduites à quelques passages chez les historiens arabes et à la Chronique fung, un texte très tardif et peu informatif sur lequel 
nous reviendrons. L'archéologie n'aide guère, puisque seules quelques petites portions des immenses ruines de la capitale, Soba, ont été fouillées par les équipes britanniques dirigées par P.L. Shinnie dans les années 1950 et D. Welsby dans les années 1980. Les sources arabes ne concernent pas directement Alodia mais une principauté située au nord du royaume, appelée al-Abwab («les portes» en arabe) où al-Aswani plaçait au $\mathrm{x}^{\mathrm{e}}$ siècle la frontière entre Makouria et Alodia. À la fin du XIII siècle, cette principauté semble avoir pris son indépendance. Son roi, Adour, entretient avec l'Égypte mamelouke de bonnes relations diplomatiques mais n'hésite pas à porter les armes contre le royaume de Makouria. Il est donc possible que la chute d'Alodia ait commencé bien plus tôt par le démembrement de son territoire. Si le royaume chrétien du sud était trop loin de l'Égypte pour craindre les assauts des armées mameloukes, il dut faire face à partir du $\mathrm{XIII}^{\mathrm{e}}$ siècle aux attaques incessantes des tribus arabes (ou du moins arabisées) qui commençaient à se déverser sur tout le territoire soudanais. Mais c'est un peuple noir récemment islamisé - les Fungs, venus du sud — qui acheva le démembrement d'Alodia en 1504 .
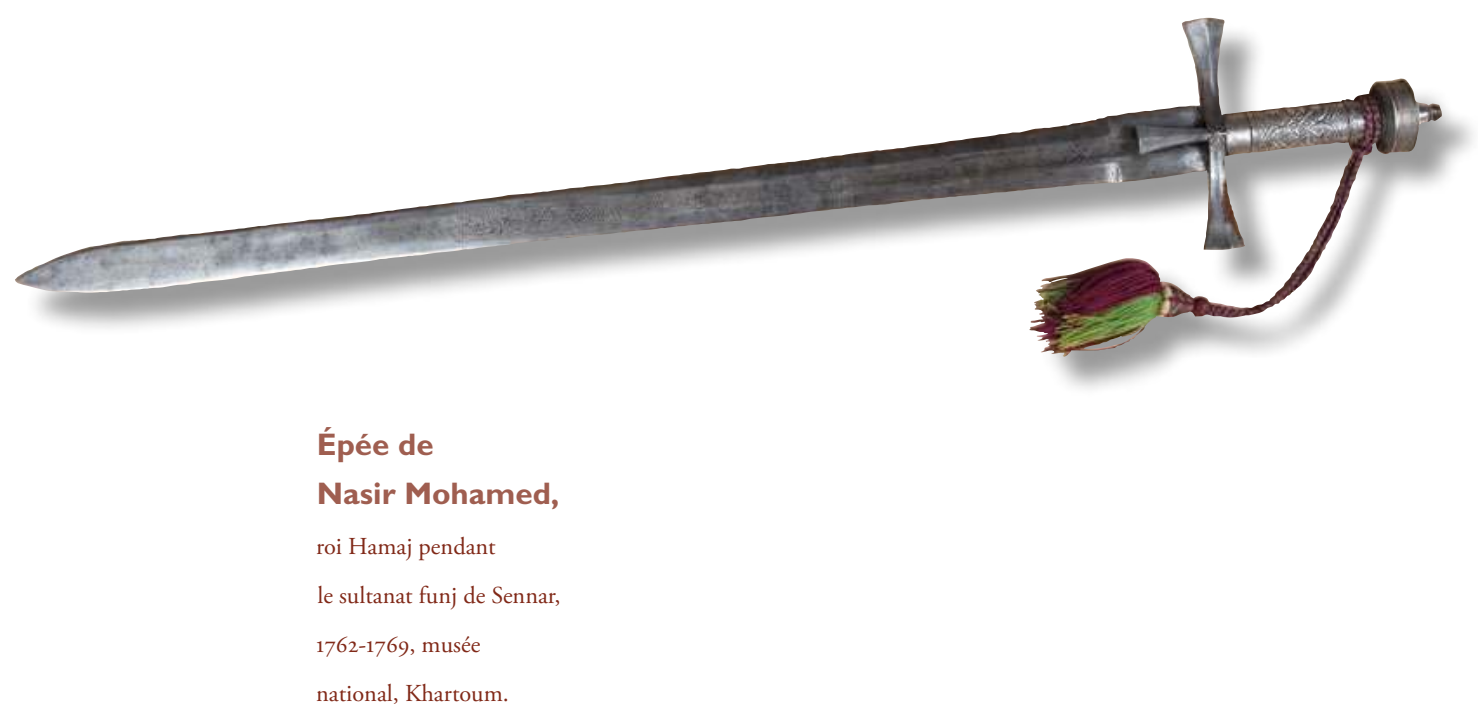

Épée de

Nasir Mohamed,

roi Hamaj pendant

le sultanat funj de Sennar,

national, Khartoum. 